\title{
Heat Transfer in Film Boiling of Flowing Water
}

\author{
Yuzhou Chen \\ China Institute of Atomic Energy \\ China
}

\section{Introduction}

Film boiling is a post critical heat flux (CHF) regime with such a high surface temperature, that the wall can not contact with the liquid, but is covered by the vapor and thus has relatively low heat transfer efficiency due to poor heat conductivity of the vapor. The film boiling is encountered in various practices, e.g., the metallurgy, the refrigeration, the chemical and power engineering, etc.. In a postulated break loss of coolant accident of nuclear reactors the uncovered core would experience this regime, and the maximum fuel temperature would be primarily dominated by the heat transfer of film boiling. Due to its significant importance to the applications the film boiling has received extensive investigations both experimentally and theoretically. It was one of three subjects in a coordinated research program on Thermal-hydraulic relationships for advanced watercooled reactors, which was organized by the International Atomic Energy Agency (1994 1999). A comprehensive review on these investigations has been presented in the technical document (IAEA-TECDOC-1203, 2001)

In film boiling the heat is transferred from the wall to the vapor, then from the vapor to the liquid, characterized by non-equilibrium. The interaction between two phases dominates the vapor generation rate and the superheat, associated with extremely complicated characteristics. This presents a major challenge for the estimation of heat transfer because of less knowledge on the interfacial processes. In particular, due to the peculiar feature of the boiling curve it is difficult to establish the film boiling regime at stable condition in a heat flux controlled system by using a conventional experimental technique. As shown in Fig.1, the stable film boiling regime can only be maintained at a heat flux beyond the CHF, which associates with an excessively high surface temperature for water. But for a heat flux, $\mathrm{q}$, below the $\mathrm{CHF}$, the regime can not be maintained stably at the post-CHF region (F or T), but at the pre-CHF region $(\mathrm{N})$.

The experimental data on film boiling were mostly obtained with refrigerant or cryogenic fluids, and the data of water were generally obtained in a temperature-controlled system or at transient condition with less accuracy. Since a so-called hot patch technique was developed for establishment of the stable film boiling regime (Groeneveld, 1974, Plummer, 1974, Groeneveld \& Gardiner, 1978), a large number of experimental data have been obtained (Stawart \& Groeneveld, 1981, Swinnerton et al., 1988, Mossad, 1988). Based on the data base various physical models have been proposed (Groeneveld \& Snoek, 1984, Groeneveld, 1988, Mossad \& Johannsen, 1989), and the tabular prediction methods have been developed for fully-developed film boiling heat transfer coefficients (Leung et al., 1997, Kirillov et al., 1996). 


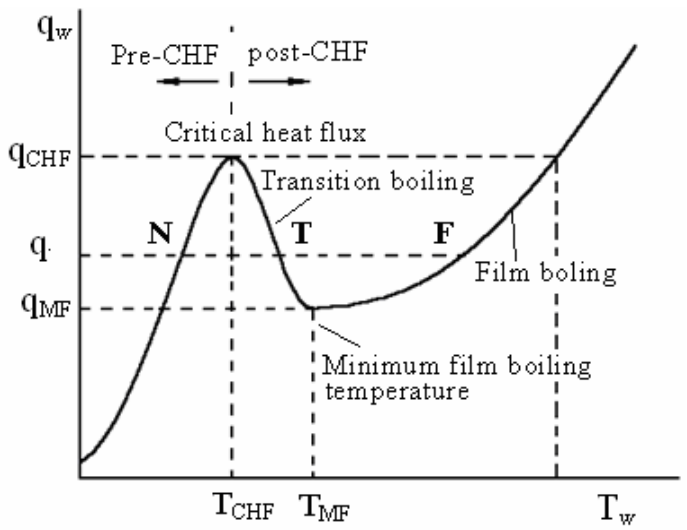

Fig. 1. Typical boiling curve

In 1984 a directly heated hot patch technique was applied by the authors to reach higher heat flux, enabling the steady-state experiment to cover extended range of conditions (Chen $\& \mathrm{Li}, 1984)$. The results fill the gaps of data base, especially in the region of lower flow, where thermal non-equilibrium is significant, associated with much complicated parametric trends and strongly history-dependent features of the heat transfer coefficient (Chen, 1987, Chen et al., 1989, Chen \& Chen, 1994). With these unique data the film boiling has been studied systematically and the prediction methods have been suggested, as will be shown in the following paragraphs.

\section{Steady-state experimental technique}

The hot patch technique is to supply separate power to a short section just ahead of the test section to reach $\mathrm{CHF}$, preventing the rewetting front from moving forward. It was first used in freon and nitrogen experiments (Groeneveld, 1974, Plummer, 1974). To increase the power of hot patch for the experiment of water, it was improved by Groeneveld \& Gardiner (1978), using a big copper cylinder equipped with a number of cartridge heaters.

To reach further high heat flux, a directly heated hot patch technique was applied by the authors (Chen \& Li, 1984). As shown schematically in Fig.2, the test section included two portions, $\mathrm{AB}$ and $\mathrm{BC}$, with each heated by a separate supply. The length of section $\mathrm{AB}$ was $10-25 \mathrm{~mm}$. Near the end (B) the wall thickness was reduced locally, so that a heat flux peak can be created there by electric supply due to higher electric resistance.

During experiment, at first the inlet valve of the test section was closed, and the water circulation was established in a bypass at desired pressure, flow rate and temperature. The test section was then heated by switching on two supplies with it in empty of water. When the wall temperature reached above $500{ }^{\circ} \mathrm{C}$, the flow was switched from the bypass to the test section. As the rewetting front moved upward the power to the upstream section was increased to reach $\mathrm{CHF}$ at the end (B), where the rewetting front was arrested without an excessive increase in the wall temperature as a result of axial heat conduction. In the same way, another rewetting front was arrested at the end of section $\mathrm{BC}$ by the upper hot patch. Therefore, the stable film boiling regime was maintained on the section $\mathrm{BC}$ with heat flux below the CHF. Shown in Fig.3 are the pictures of stable film boiling in an annulus for different water temperatures with the hot patch on and a reflooding transient with the hot patch off. 


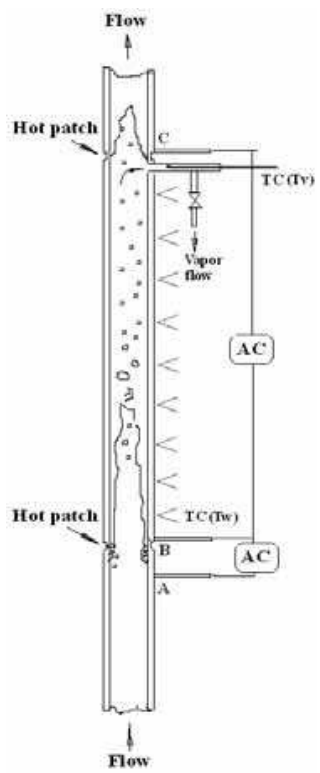

Fig. 2. Schematic of the test section with measurements of both the wall and vapor temperatures

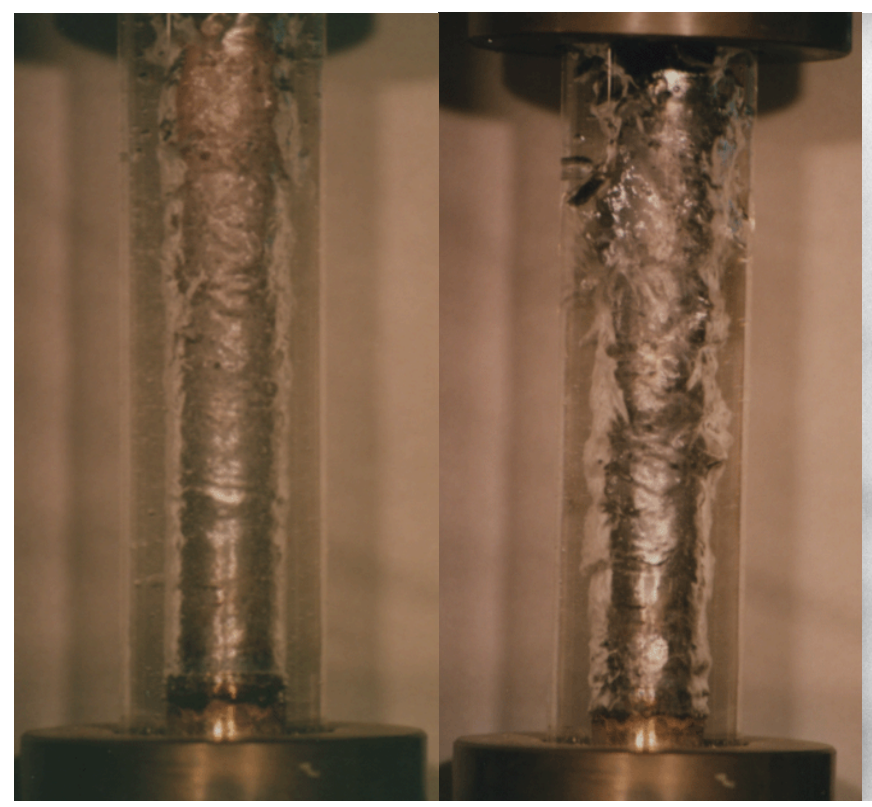

(a)

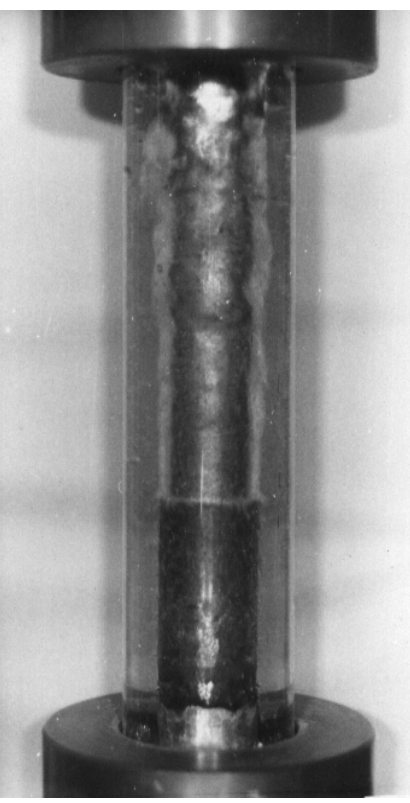

(c)

Fig. 3. Inverted annular film boiling in an annulus with water flowing upward (a) and (b): Stable regime (with the hot patch on), $\mathrm{T}_{\mathrm{l}, \mathrm{a}}<\mathrm{T}_{\mathrm{l}, \mathrm{b}}$, (c): Reflooding transient (with the hot patch off) 
The steady-state film boiling experiments have been performed with water flowing upward in tubes of $6.7-20 \mathrm{~mm}$ in diameter and $0.15-2.6 \mathrm{~m}$ in length, covering the ranges of pressure of $0.1-6 \mathrm{MPa}$, mass flux of $23-1462 \mathrm{~kg} / \mathrm{m}^{2} \mathrm{~s}$ and inlet quality of $-0.15-1.0$.

\section{Characteristics of the heat transfer in film boiling}

The term "film boiling" was originally used for a post-CHF regime in a pool, characterized by the wall separated from the stagnant liquid by a continuous vapor film. It was then used in forced flow, though the flow pattern varied with the enthalpy in the channel. It includes two major regimes: 1) the inverted annular film boiling (IAFB), which occurs at subcooled or low quality condition, and 2) the dispersed flow film boiling (DFFB), which occurs at saturated condition with the void fraction larger than around 0.8. In IAFB the vapor film separates the wall from the continuous liquid core, in which some bubbles might be entrained for saturated condition. The DFFB is characterized by liquid droplets entrained in the continuous vapor flow. It can be resulted from break-up of the IAFB or from dryout of the liquid film in an annular flow. Fig.4 shows the film boiling regimes in a bottom reflooding transient at different flooding rates.

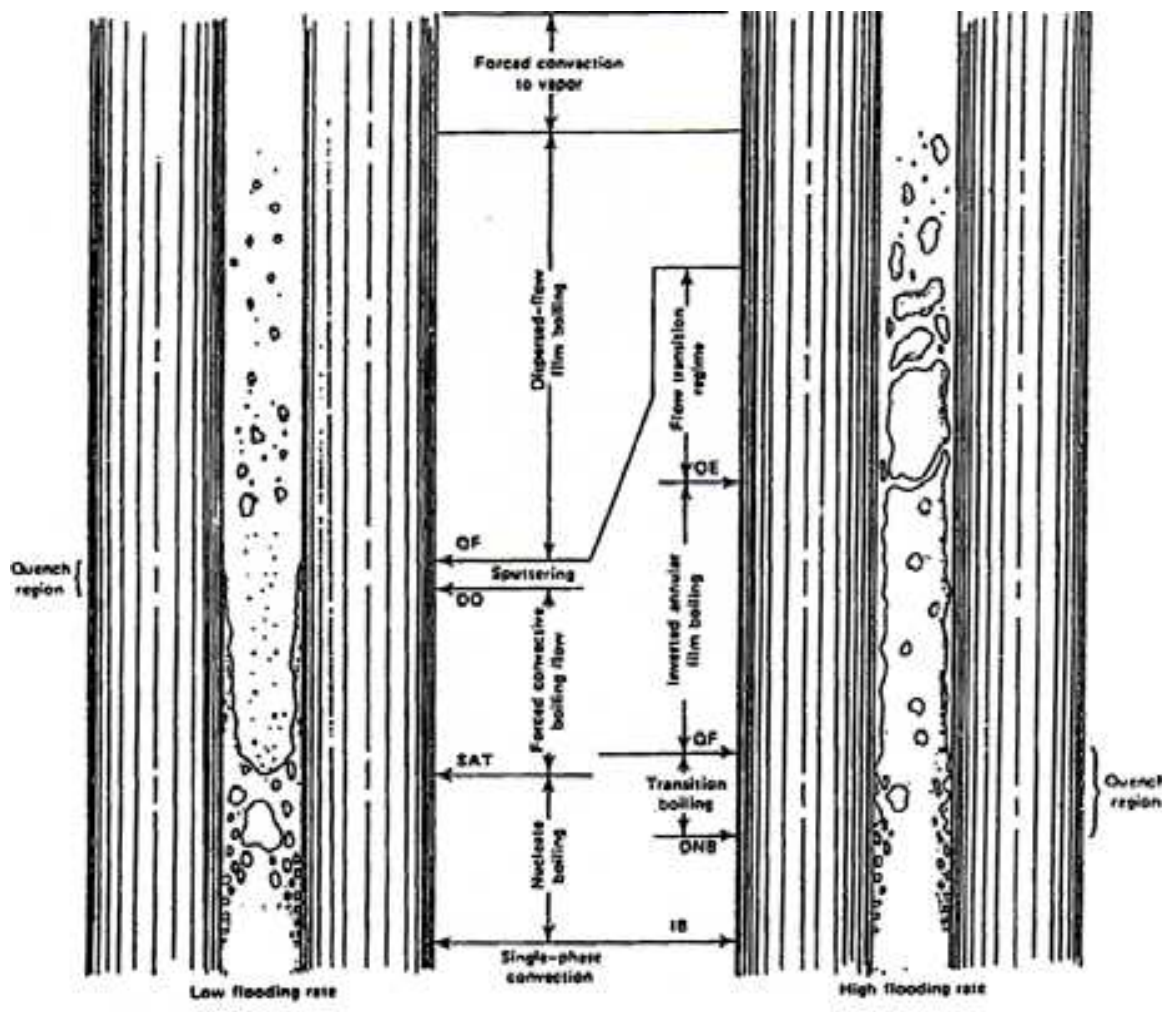

(a) lower inject rate

(b) higher inject rate

Fig. 4. Film boiling regimes during reflooding with different flooding rates (Arrieta \& Yadigaroglu, 1978) 
Typical experimental results are exemplified in Fig.5, where the heat transfer coefficient distributions in a tube for different inlet qualities are displayed by $h\left(=q_{w} /\left(T_{w}-T_{s}\right)\right)$ versus $\mathrm{x}_{\mathrm{E}}$. For subcooled (run no.1) and low quality (run no. 2) inlet condition the post-CHF region initiates with IAFB followed by DFFB. While for relatively high inlet quality (run no. 3 and 4) the DFFB covers the whole post-CHF region. As seen, lower heat transfer coefficients are attained in the transition region.

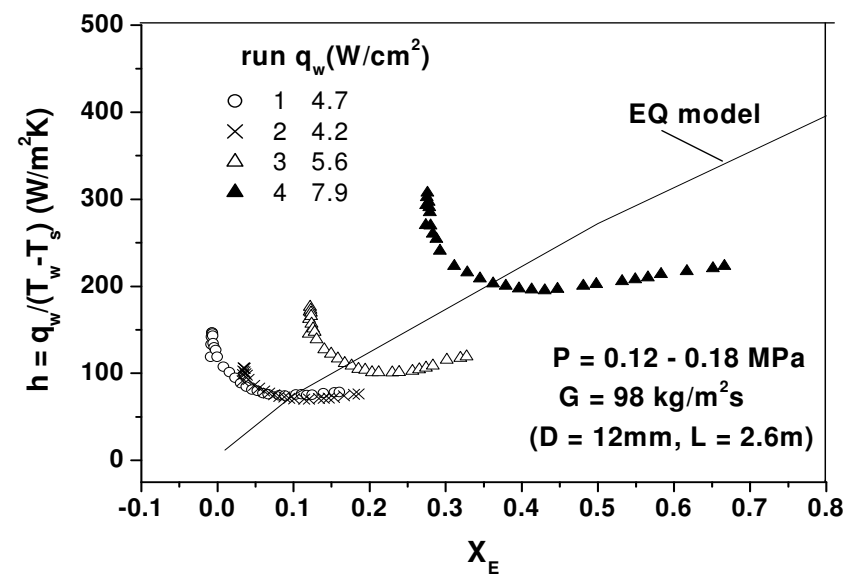

Fig. 5. Distributions of the heat transfer coefficients along the length for different inlet qualities

\subsection{Inverted annular film boiling}

In IAFB the heat is transferred by convection and radiation from the wall to the vapor, subsequently from the vapor to the interface with liquid. For subcooled condition it is then partially transferred to the liquid core. At the interface the vaporization takes place and the vapor generation rate is determined by the heat flux to the interface minus that to the liquid core. As the increase of vapor generation the vapor flow in the film may transit from laminar to turbulent. Furthermore, the interaction between two phases could result in interface oscillation, having enhancement effect on the heat exchange in both the vapor film and the liquid core.

\subsubsection{Effects of the pressure, mass flux and subcooling}

Fig. 6 shows the distributions of heat transfer coefficients $\left(h=q_{w} /\left(T_{w}-T_{s}\right)\right)$ under different conditions. For lower flow with higher subcooling the $\mathrm{h}$ decreases rapidly with distance, while as subcooling decreasing the $\mathrm{h}$ decreases, and the trend becomes mild (Fig.6(a)). For higher flow with higher subcooling a maximum $h$ is attained at a few centimeters from the dryout point (Fig.6(b,c)). In this case the thickness of vapor film is very small, so the interface oscillation could lead to dry-collision between liquid and wall, resulting in a substantial increase in the $h$. For low inlet subcooling the variation of $h$ along the length is not substantial (Fig.6(f)). This suggests that as the distance increases the negative effect of the increase in thickness and the positive effect of disturbance in the vapor film are comparable on the heat transfer. 
At higher pressure the heat transfer coefficients are generally higher than those at lower pressure for low subcooling or saturation condition (Fig. 6(e, f). An opposite effect is observed for higher flow and higher subcooling (Fig. 6(d)). This can be explained in terms of the thickness of vapor film and the interface oscillation. Higher pressure corresponds to smaller volumetric vapor generation and thus smaller thickness of the film.

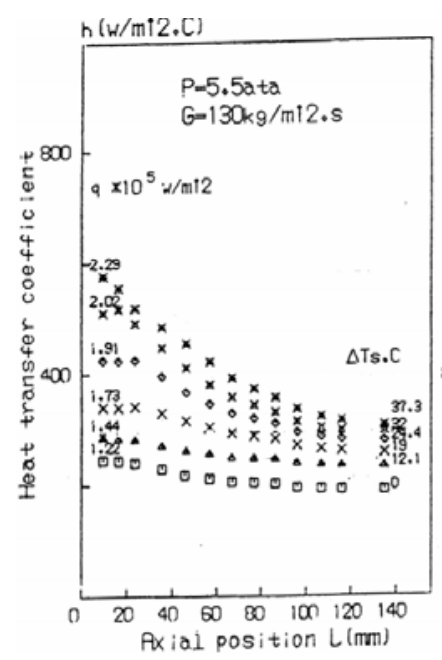

(a)

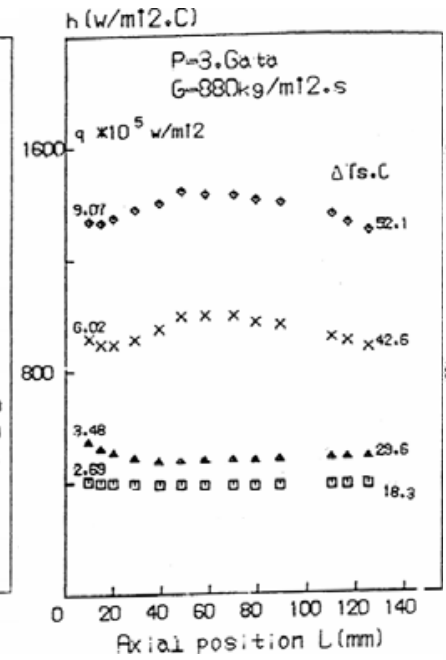

(b)

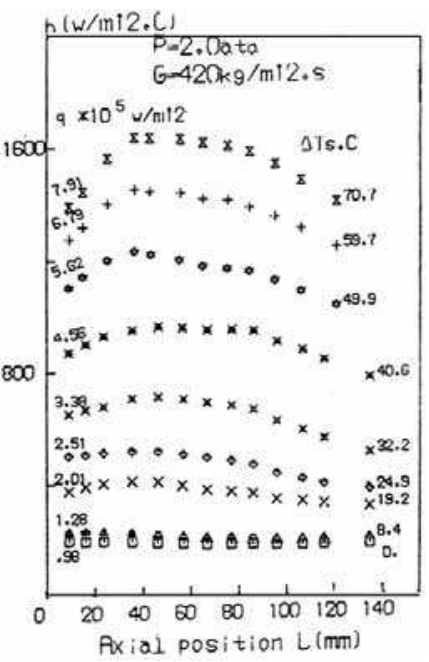

(c)

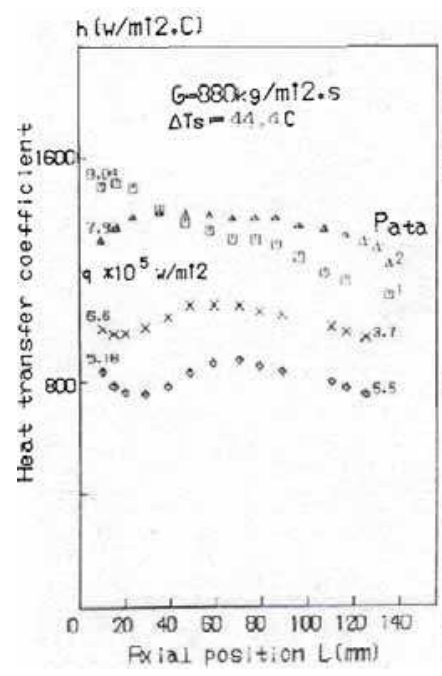

(d)

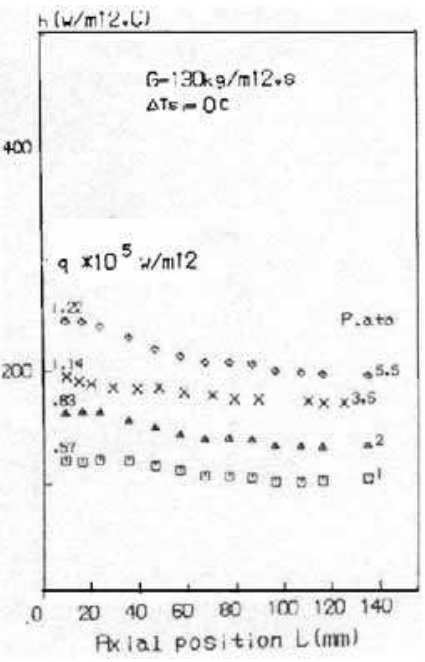

(e)

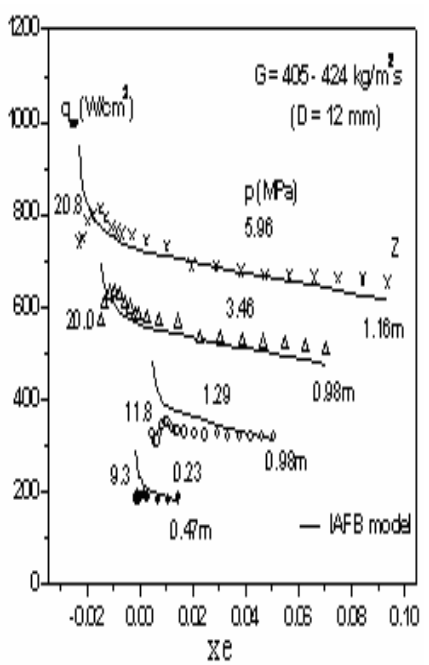

(f)

Fig. 6. Variation of the heat transfer coefficient in IAFB under different conditions (Chen, 1987) 
It results in higher $\mathrm{h}$ for low subcooling or saturated condition. Nevertheless at higher flow and higher subcooling the film is very thin, and for lower pressure there could exist stronger interface oscillation, even dry-collision of liquid to wall, which has predominant effect on the heat exchange in both the vapor film and the liquid core. While for higher pressure this effect is less important due to less interface oscillation.

\subsubsection{Effect of the preceding heating}

To clarify the effect of preceding heating, an additional power supply was provided to a section of $L=225 \mathrm{~mm}$ immediately ahead of $A B$ (with heat flux $q_{0}$ ). When the $q_{0}$ exceeded a value for the onset of boiling a substantial fall in the $T_{w}$ was attained over the first about 100 mm for fixed $\mathrm{p}, \mathrm{G}$ and $\Delta \mathrm{T}_{\mathrm{s}}$ at the dryout point, as shown in Fig.7 (Chen, 1987). In this case a bubble layer was produced upstream, which was determinant for the vapor flow rate and the interfacial oscillation over a certain length near the dryout point. For high subcooling the vapor film was very thing, and this effect could be more substantial. Nevertheless, at a $\mathrm{q}_{0}$ without boiling the $\mathrm{T}_{\mathrm{w}}$ near the dryout point was increased slightly. In this case a temperature profile was developed in the subcooled liquid core, which would result in lower heat transfer coefficient from the interface to liquid core, compared to that with uniform core temperature for the same average temperature.

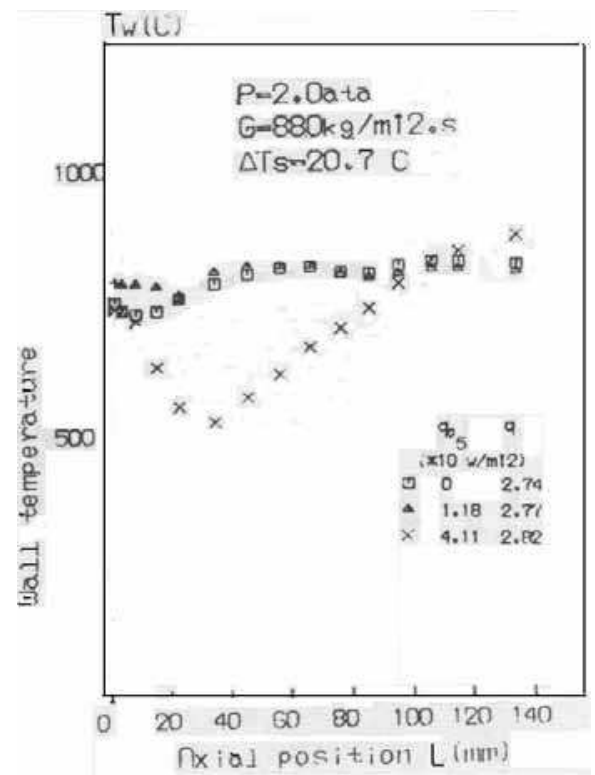

Fig. 7. Effect of the preceding heating power on the wall temperature (Chen, 1987)

\subsection{Dispersed flow film boiling}

In DFFB the heat is transferred from the wall to the vapor, then from the vapor to the liquid droplets entrained in the continuous vapor flow. The wall temperature is mainly dominated by the vapor convection heat transfer and the vapor temperature. The liquid droplets would induce some disturbance for the vapor convection, and the vapor-droplet interfacial heat 
transfer determines the vapor temperature. This effect is closely relative with the flow conditions, associated with complicated parametric trends of the wall temperature.

\subsubsection{Effects of the pressure, mass flux and inlet quality}

Typical distributions of the $\mathrm{h}\left(=\mathrm{q}_{\mathrm{w}} /\left(\mathrm{T}_{\mathrm{w}}-\mathrm{T}_{\mathrm{s}}\right)\right)$ along the length are shown in Fig.8. In general, as distance increases from the dryout point, at first the $\mathrm{h}$ decreases rapidly. For lower flow it decreases monotonously over the whole length, though the trend becomes milder downstream. For higher flow the $\mathrm{h}$ turns to increase after a certain distance. This behavior varies distinctly with pressure. At $p<0.2 \mathrm{MPa}$, for instance, the increase trend in the $h$ is observed at mass flux below $300 \mathrm{~kg} / \mathrm{m}^{2} \mathrm{~s}$, while for higher pressure it is attained at higher mass flux.

In addition to the local parameters, $p, G$ and $x_{e}$, the inlet quality (at the dryout point) has a significant effect on the $h$. As seen, for the same pressure and mass flux with different inlet quality, different $\mathrm{h}$ may be attained at a fixed local $\mathrm{x}_{\mathrm{e}}$, and higher $\mathrm{h}$ corresponds to higher inlet quality, exhibiting a strongly history-dependent feature. This is understandable due to the fact that to reach a same $x_{\mathrm{e}}$ the flow with higher inlet quality subjects to less heat transfer and thus less superheat of vapor. At low flow this effect is so significant, that the fullydeveloped condition can not be reached even at $\mathrm{L}>2 \mathrm{~m}$ or $\mathrm{L} / \mathrm{D}>200$.

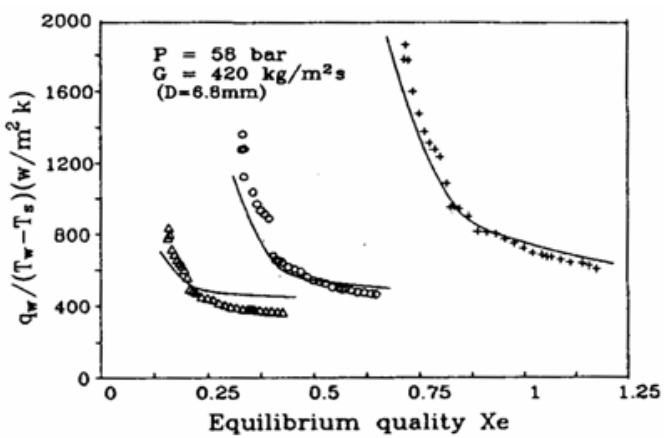

(a)

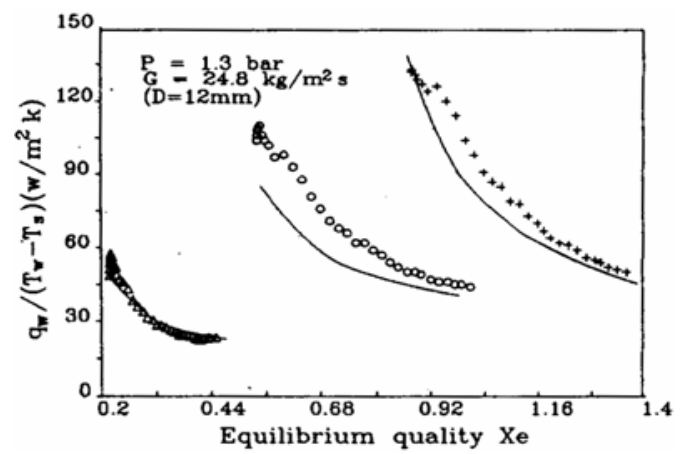

(c)

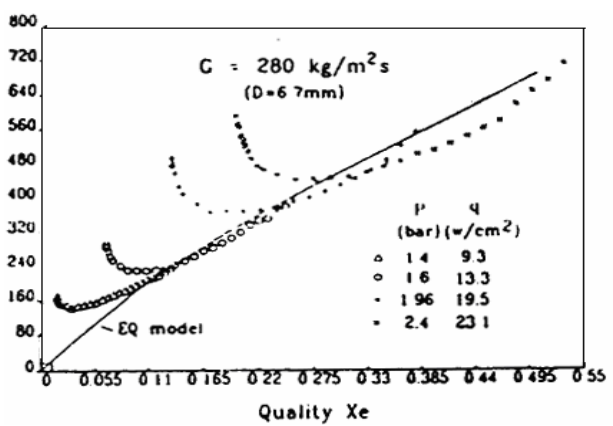

(b)

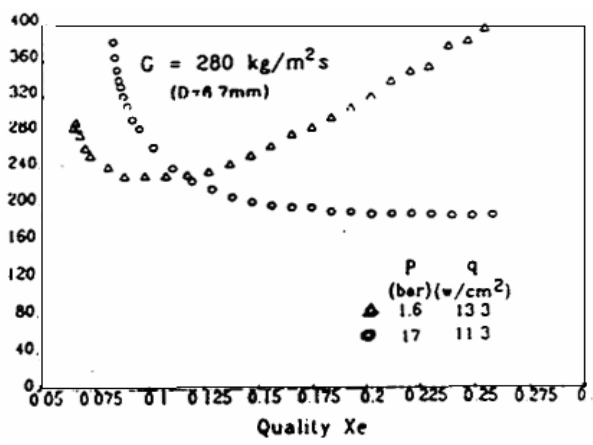

(d) 


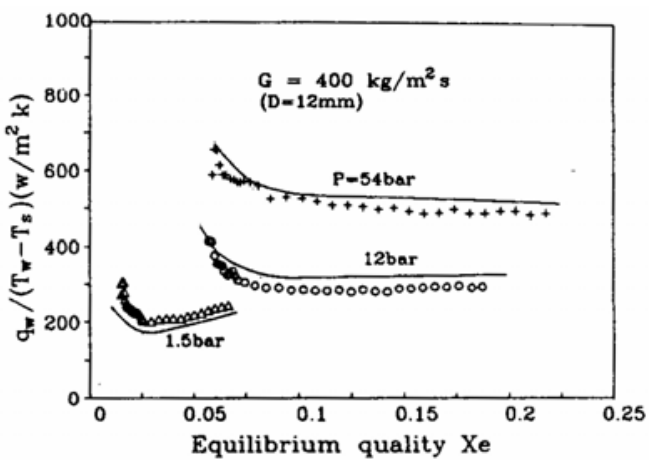

(e)

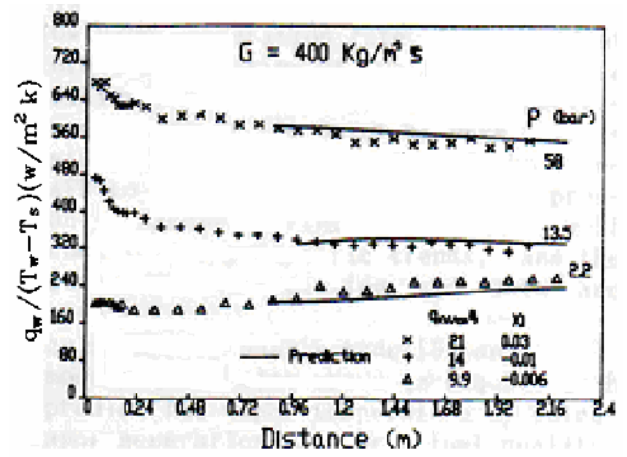

(g)

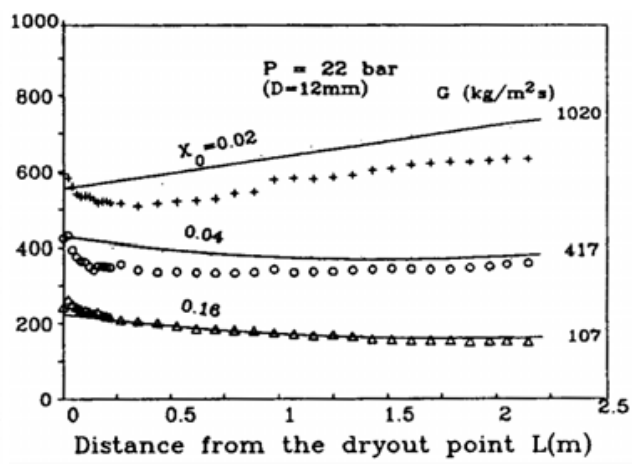

(f)

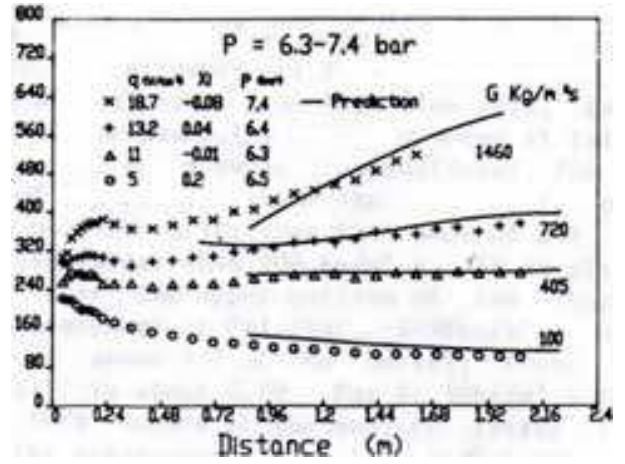

(h)

Fig. 8. Variations of heat transfer coefficient for different conditions in DFFB (- mechanistic model), (a-f): DFFB covering the whole post-CHF region; ( $\mathrm{g}, \mathrm{h})$ : DFFB preceded by IAFB (Chen et al., 1991, 1992, 1994b)

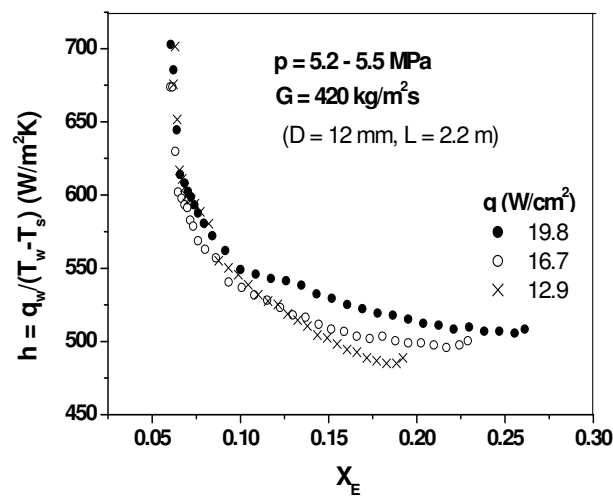

(a)

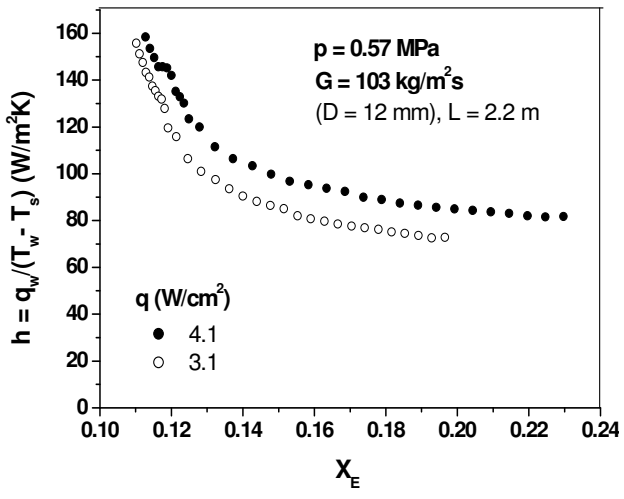

(b)

Fig. 9. Effect of heat flux on the heat transfer coefficients in DFFB 


\subsubsection{Effects of other factors}

The effect of heat flux on the $\mathrm{h}$ is shown in Fig.9. Higher heat flux corresponds to higher h. This is mainly attributed to the increase in the radiation heat transfer due to higher wall temperature at higher heat flux. Fig.10 shows the effect of diameter on the h. In general, smaller diameter corresponds to lower heat transfer coefficients over the downstream. It is expectable that for same heat flux and mass flux smaller diameter corresponds to greater increase rate of the enthalpy along the length, leading to stronger thermal non-equilibrium and thus lower $h$.

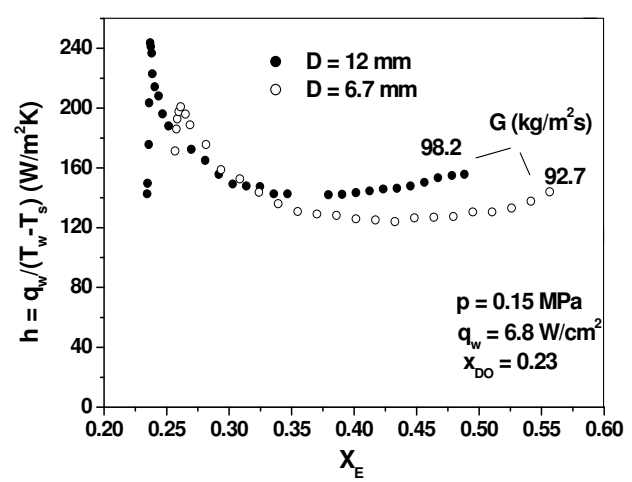

(a)

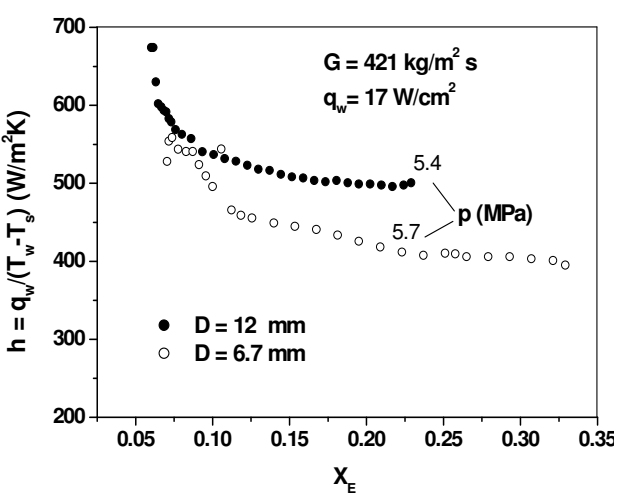

(b)

Fig. 10. Effect of diameter on the heat transfer coefficients in DFFB

\subsubsection{Thermal non-equilibrium}

The complicated parametric trends of the heat transfer in DFFB are closely related to the thermal non-equilibrium, which is determined by the fraction of total heat to the vapor for superheating. The following thermal non-equilibrium parameter was defined by Plummer et al. (1977),

$$
K=\frac{x-x_{0}}{x_{e}-x_{0}}
$$

with

$$
x=x_{e}\left(1+\frac{C_{p g}\left(T_{v}-T_{s}\right)}{h_{f g}}\right)^{-1}
$$

where the $T_{v}$ and $T_{s}$ are the vapor temperature and saturation temperature, respectively, the $\mathrm{x}_{0}$ is the quality at the dryout point, and the $\mathrm{x}$ and $\mathrm{x}_{\mathrm{e}}$ are the local actual quality and equilibrium quality, respectively. 
The case of $K=1$ represents the thermal equilibrium, in which all the heat from the wall goes to liquid for evaporation and the vapor temperature keeps at constant $\left(T_{s}\right)$, so the $h$ increases along the length as the vapor flow rate increasing. The case of $K=0$ represents that all the heat goes to the vapor for superheating without vapor generation, so the $T_{w}$ increases as the $T_{v}$ increasing and thus the $\mathrm{h}$ decreases monotonously. Fig.11 illustrates the substantial effect of the K on both the values and the trends of the heat transfer coefficient.

Using a technique to prevent the probe from striking by the liquid droplets and from the effect of radiation, the data of vapor superheat were successfully obtained in steady-state film boiling experiments near the exit of test section (Chen, 1992, Chen \& Chen, 1994a). The values of $K$ and ratio of $\left(T_{v}-T_{s}\right) /\left(T_{w}-T_{s}\right)$ were then evaluated from the vapor superheats measured at $2 \mathrm{~m}$ from the dryout point, as shown in Fig.12. For low $\mathrm{X}_{0}$, the $\mathrm{K}$ decreases as $\mathrm{X}_{0}$ increasing. At certain increased $X_{0}$ the trend becomes milder. It varies distinctly with pressure, and higher $K$ is attained at lower pressure. The ratio $\left(T_{v}-T_{s}\right) /\left(T_{W}-T_{s}\right)$ decreases with mass flux. For $G<100 \mathrm{~kg} / \mathrm{m}^{2} \mathrm{~s}$, the $\left(\mathrm{T}_{\mathrm{v}}-\mathrm{T}_{\mathrm{s}}\right) /\left(\mathrm{T}_{\mathrm{w}}-\mathrm{T}_{\mathrm{s}}\right)$ is larger than 0.5 , suggesting a major contribution of the vapor superheat to the wall superheat. For $G<50 \mathrm{~kg} / \mathrm{m}^{2} \mathrm{~s}$ the thermal non-equilibrium is much significant, so that the $T_{v}$ and $T_{w}$ increase significantly along the length, and the $h\left(=q_{w} /\left(T_{w}-T_{s}\right)\right)$ exhibits sharp decrease trend. The effects of various parameters on the thermal non-equilibrium can be explained in terms of droplet size and concentration, the vapor-droplet relative velocity and heat transfer coefficient, the properties, etc.. This is made clear in the analysis with the two-fluid mechanistic model.

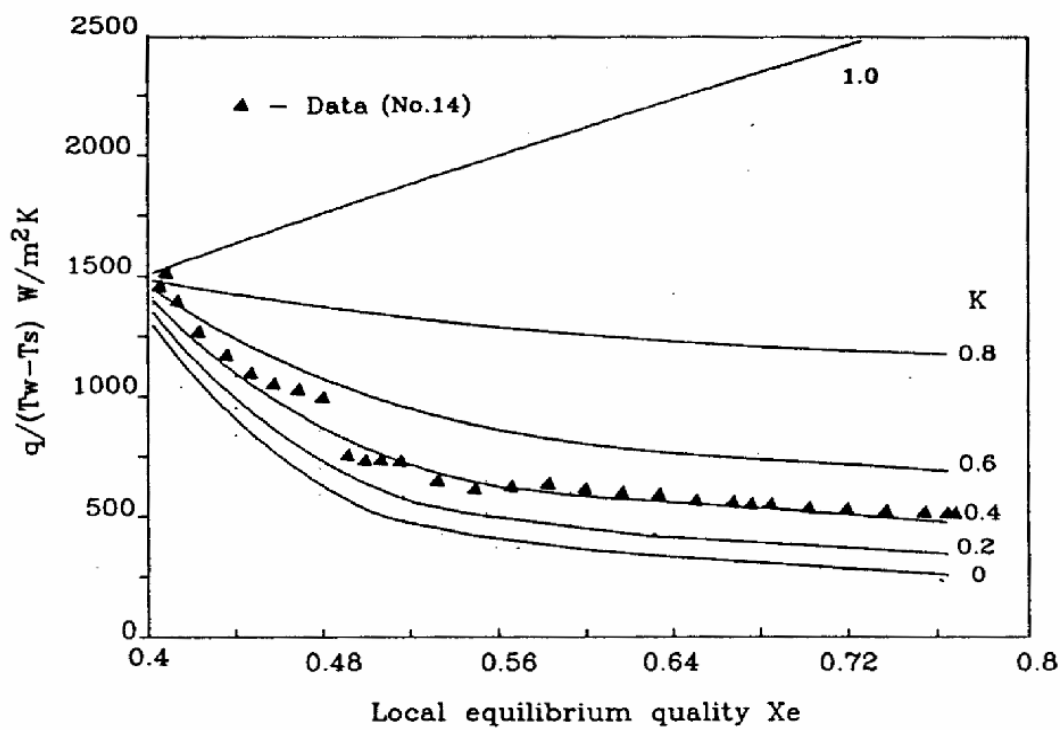

Fig. 11. Variations of the heat transfer coefficient along the length for different $K(p=5.8$ $\mathrm{MPa}, \mathrm{G}=417 \mathrm{~kg} / \mathrm{m}^{2} \mathrm{~s}, \mathrm{x}_{\mathrm{DO}}=0.383, \mathrm{D}=6.8 \mathrm{~mm}$ ) (Chen, et al., 1992) 


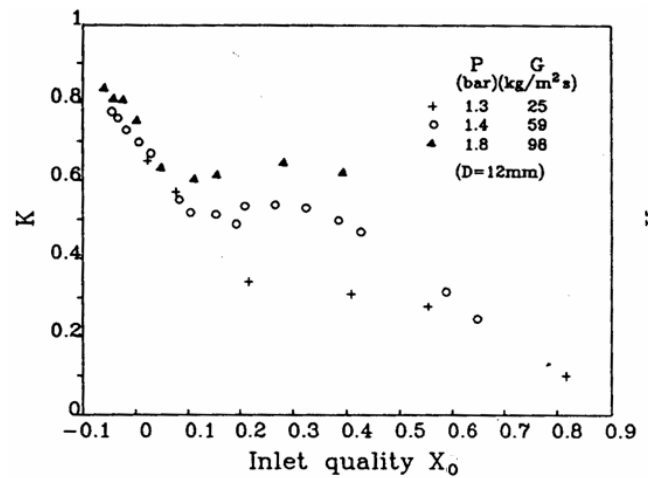

(a)

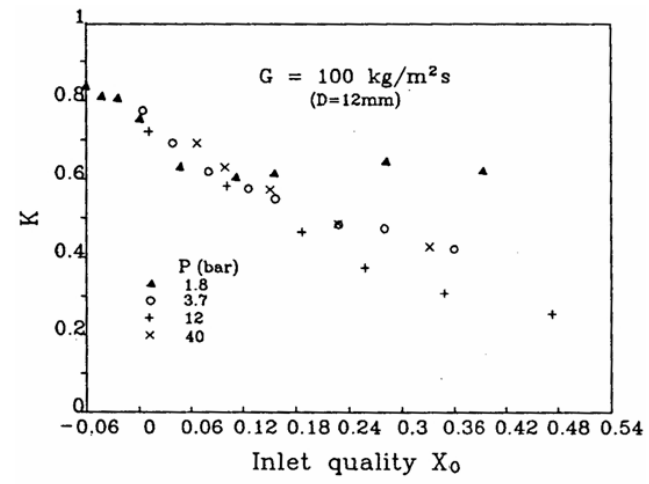

(c)

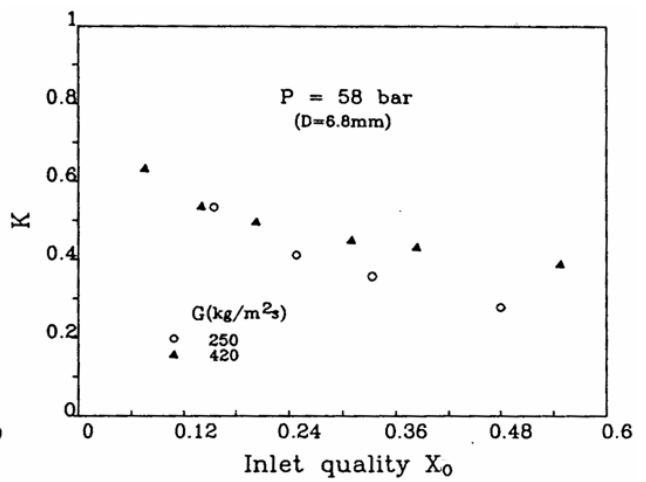

(b)

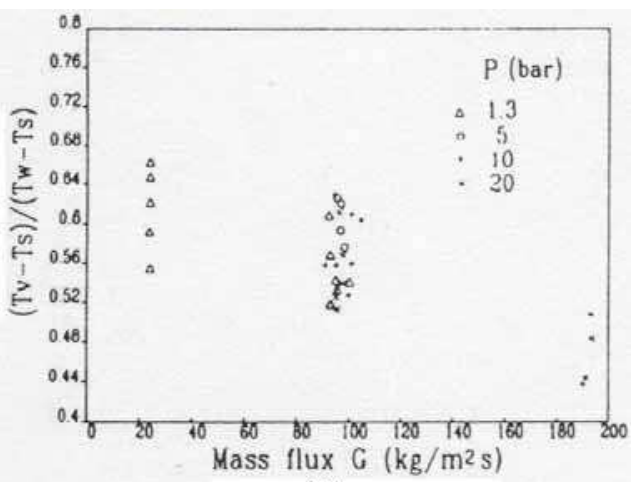

(d)

Fig. 12. Variations of the $K$ with $\mathrm{x}_{0}$ and $\left(\mathrm{T}_{\mathrm{v}}-\mathrm{T}_{\mathrm{s}}\right) /\left(\mathrm{T}_{\mathrm{w}}-\mathrm{T}_{\mathrm{S}}\right)$ with $\mathrm{G}$ for different conditions (Chen \& Chen, 1994a, Chen, et al., 1992)

\subsection{Minimum film boiling temperature}

The minimum film boiling temperature, $\mathrm{T}_{\min }$, defines the boundary between the film boiling and the transition boiling, in which the wall contacts with the liquid intermittently and thus has much higher heat transfer coefficient than the film boiling. The collapse of film boiling could be resulted from the thermodynamic limit or the hydrodynamic instability. During a fast transient it could be thermodynamically controlled, while for low flow and low pressure it is likely to be hydraudynamically controlled. Six types of the film boiling termination mechanisms have been identified: (1) collapse of vapor film, (2) top flooding, (3) bottom flooding, (4) droplet cooling, (5) Leidenfrost boiling and (6) pool boiling. Significant discrepancies were found among the existing correlations of the $\mathrm{T}_{\mathrm{min}}$, and were attributed to the different types of the mechanism and scarcity of reliable data (Groeneveld \& Snoek, 1984). With the hot patch technique the minimum film boiling temperatures were measured in steady-state film boiling experiments by decreasing the power to the test section slowly with small steps until the collapse of film boiling occurred. The following empiric correlation was formulated from an experiment over the ranges of $\mathrm{p}=115-6050 \mathrm{kPa}, \mathrm{G}=53-1209 \mathrm{~kg} / \mathrm{m}^{2} \mathrm{~s}$, $\mathrm{x}=-0.055-0.08$ and $\Delta \mathrm{T}_{\mathrm{s}}=-35-25.1 \mathrm{~K}($ Chen, 1989), 


$$
T_{\min }=363,6+38.37 \ln p+0.02844 p-3.86 \times 10^{-6} p^{2}+a \Delta T s
$$

with

$$
a=17.1 /(3.3+0.0013 p) \quad \text { for } \Delta T s>0
$$

and

$$
a=0
$$

for $\Delta T s \leq 0$

where the $p$ is in $\mathrm{kPa}$ and the $T_{\min }$ and $\Delta \mathrm{T}_{\mathrm{s}}$ in $\mathrm{K}$.

This correlation is in reasonable agreement with that derived from a similar experiment by Groeneveld and Steward (1982). It can be recommended for type (1-4) of film boiling termination.

\section{Predictions for the heat transfer coefficients}

As described above, the film boiling is characterized by non-equilibrium in both the velocity and temperature between phases, associated with extremely complicated parametric trends. The steady-state experimental data obtained in tube with flowing water were compared with the existing correlations, and significant discrepancies were observed between them, as shown in Fig.13. This result revealed the suspect of the correlations, and it was attributed to the lack of reliable data base and the difficulty in accounting for various physical mechanisms in a simple correlation (Stewart and Groeneveld, 1982, Groeneveld \& Snoek, 1984). With steadystate technique the accuracy of the experimental data was improved substantially. As shown in Fig.14, the present steady-state data are in well agreement with those obtained by Swinnerton et al (1988) using indirectly heated hot patch technique for similar conditions.

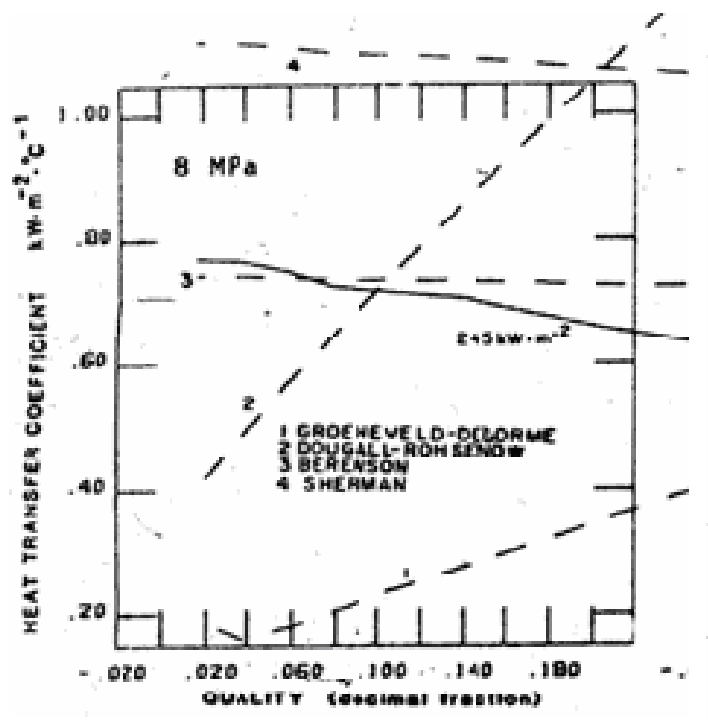

(a)

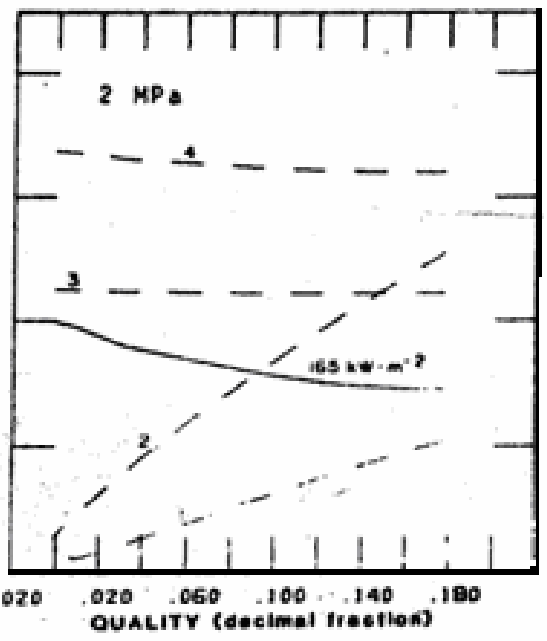

(b)

Fig. 13. Comparison of the steady-state experimental data of water with existing correlations (Stewart and Groeneveld, 1982) 
To predict the non-equilibrium characteristics in film boiling the two-fluid models are favorable, and have been proposed by many investigators (Groeneveld, 1988, 1992, Mossad \& Johannsen, 1989). The major challenge for these models is to simulate the interfacial heat and momentum exchanges. Due to less knowledge on these processes they were generally accounted by empiric or semi-empiric correlations. Therefore, the suitability of this kind of models is heavily determined by the ranges and the accuracy of data base. The following two-fluid models are developed based on the present experimental data.

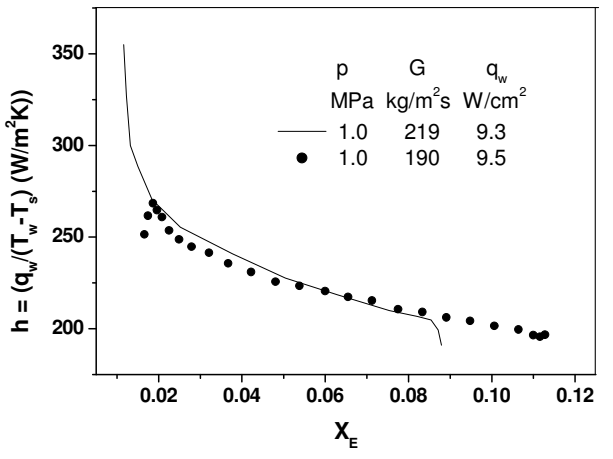

(a)

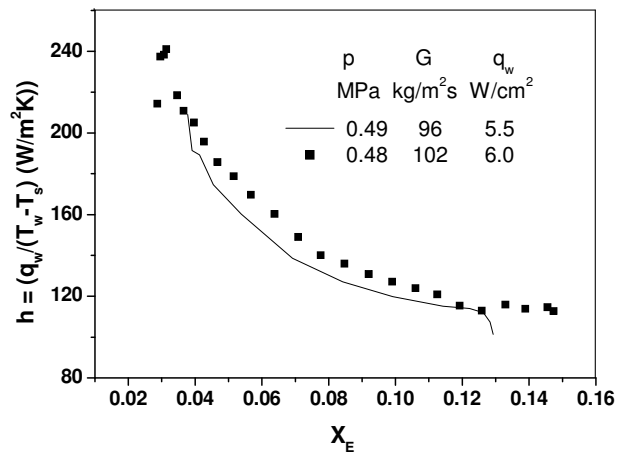

(b)

Fig. 14. Comparison of the results obtained in different steady-state experiments with water flowing in tube (-Swinnerton, et al. $\mathrm{D}=9.75 \mathrm{~mm}$, $\bullet$ Present experiment, $\mathrm{D}=12 \mathrm{~mm}$ )

\subsection{IAFB model}

The schematic of flow structure in IAFB is shown in Fig.15, in which the vapor film is divided into two regions, $\mathrm{A}$ and $\mathrm{B}$, bounded with the locus of the maximum velocity line.

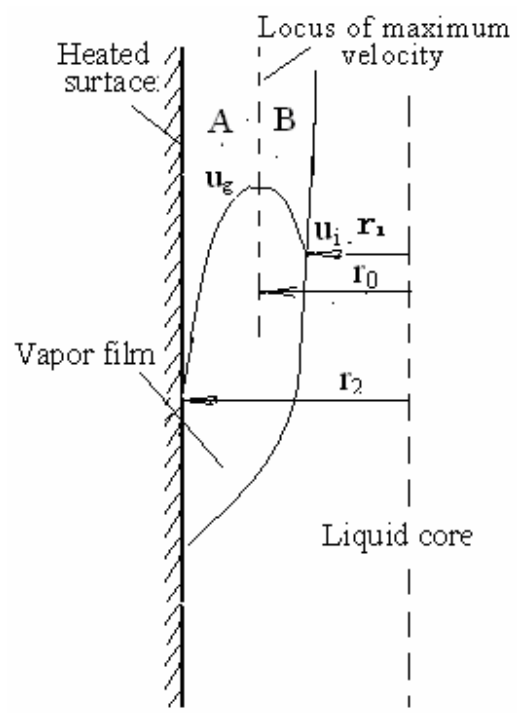

Fig. 15. Inverted annular film boiling mode 
The assumptions are as follows:

- The pressure over a cross section is uniform.

- The kinetic energy and viscous dissipation and pressure loss due to acceleration are negligible.

- $\quad$ The properties of vapor are evaluated at $\left(T_{w}+T_{s}\right) / 2$.

- The vapor-liquid interface is treated as smooth, and both the vapor and the liquid at the interface are at saturation.

- The velocity profile in the liquid core is uniform and equal to the vapor velocity at the interface.

In vapor film the force balance gives

$$
\mu_{v}\left(1+\frac{\varepsilon_{v}}{v_{v}}\right) \frac{d u}{d r}+\frac{r^{2}-r_{0}^{2}}{2 r}\left(\rho_{v} g+\frac{d p}{d z}\right)=0
$$

with boundary conditions as

$$
u=0 \text { at } r=r_{2}
$$

and

$$
u=u_{i}=\overline{u_{l}} \text { at } r=r_{i}
$$

where $\overline{u_{l}}$ is the average velocity in the core.

Neglecting the weight of vapor, the integration of Eq.(3) gives, for region $\mathrm{A}$

and for region $B$

$$
u_{g}=\frac{1}{2 \mu_{v}\left(1+\varepsilon_{v} / v_{v}\right)} \frac{d p}{d z}\left[r_{0}^{2} \ln \frac{r}{r_{2}}+\frac{1}{2}\left(r_{2}^{2}-r^{2}\right)\right]
$$

with

$$
u_{g}=\frac{1}{2 \mu_{v}\left(1+\varepsilon_{v} / v_{v}\right)} \frac{d p}{d z}\left[r_{0}^{2} \ln \frac{r}{r_{1}}-\frac{1}{2}\left(r^{2}-r_{1}^{2}\right)\right]+u_{i}
$$

$$
\frac{d p}{d z}=\frac{r_{1}^{2} \rho_{c} g+\left(r_{0}^{2}-r_{1}^{2}\right) \rho_{v} g}{r_{0}^{2}}
$$

where $\varepsilon_{v}$ is the eddy diffusivity in the vapor film, and the $\rho_{c}$ is the average density of the core. Some vapor may be entrained in the core, and $\rho_{c}$ is evaluated by

$$
\rho_{c}=\alpha_{c} \rho_{v}+\left(1-\alpha_{c}\right) \rho_{l}
$$

where $\alpha_{c}$ is the void fraction of the core. The following expression is attempted with adjustable factor $\mathrm{c}=40$,

$$
\alpha_{c}=\frac{1}{1+c \rho_{v} / \rho_{l} / x}
$$

Assuming the momentum eddy diffusivity $\varepsilon_{v}$ independent of $r$, by integrating Eq. (4) and (5) the vapor flow rate in the film is as 


$$
\Gamma=\frac{\pi \rho_{v}}{\mu_{v}\left(1+\varepsilon_{v} / v_{v}\right)} \frac{d p}{d z}\left[\frac{r_{0}^{4}}{2} \ln \frac{r_{2}}{r_{1}}+\frac{1}{8}\left(r_{2}^{4}-r_{1}^{4}\right)-\frac{1}{2} r_{0}^{2}\left(r_{2}^{2}-r_{1}^{2}\right)\right]+\pi u_{i} \rho_{v}\left(r_{0}^{2}-r_{1}^{2}\right)
$$

The wall heat flux is expressed as

$$
q=q_{w-i, c}+q_{w-i, r}+q_{v}
$$

where $q_{v}$ is the heat for vapor superheating, $q_{w-i, c}$ and $q_{w-i, r}$ are the heat flux to the interface by convection and by radiation, respectively, evaluated by,

$$
q_{w-i, c}=h_{c}\left(T_{w}-T_{s}\right)
$$

with

and

$$
h_{c}=\frac{k_{v}}{\delta}\left(1+\frac{\varepsilon_{v}}{v_{v}} \frac{\operatorname{Pr}_{v}}{\operatorname{Pr}_{t}}\right)
$$

$$
q_{w-i, r}=0.75 \frac{\sigma_{S B}}{\left(1 / \varepsilon_{l}+1 / \varepsilon_{w}-1\right)}\left(T_{w}^{4}-T_{s}^{4}\right)
$$

where $\delta$ is the thickness of film, and $\operatorname{Pr}_{t}$ is the turbulent Prandtl number.

The energy balance equation at the interface can be written as,

$$
q_{w-i, c}+q_{w-i, r}=q_{g}+q_{l}
$$

where $q_{l}$ is the heat flux from the interface to the core, and $q_{g}$ is the heat flux for evaporation, as

$$
q_{g}=\frac{d \Gamma}{d z} h_{f g} / 2 \pi r_{1}
$$

The mass equation is written as

$$
\Gamma+\pi r_{1}^{2} \bar{u} \rho_{c}=\pi r_{2}^{2} G
$$

From the authors experiments with saturated and low subcooling condition, the following empiric expression for $\varepsilon_{v}$ is proposed with $\operatorname{Pr}_{t}=1.0$.

with

$$
\varepsilon_{v} / v_{v}=0.011 \operatorname{Re}_{v}^{0.6} \operatorname{Re}_{l}^{0.3}
$$

$$
\operatorname{Re}_{v}=2 G x\left(r_{2}-r_{1}\right) / \mu_{v}
$$

and

$$
\operatorname{Re}_{l}=G(1-x) D_{1} / \mu_{l}
$$

For the heat transfer from interface to subcooled liquid core the following correlation is available (Alalytis \& Yadigaroglu 1987) 


$$
q_{l}=0.06\left(k_{l} / D\right) \operatorname{Re}_{l}^{0.6} \operatorname{Pr}_{l}^{0.3}\left[\mu_{v} \rho_{v} /\left(\mu_{l} \rho_{l}\right)\right]^{-0.15} \operatorname{Pr}_{v}^{0.6}\left(T s-T_{f}\right)
$$

It should be noted that for subcooled condition the $\mathrm{h}$ near the dryout point is related to the condition at the dryout point, which is determined by the preceding heating, as described above. It is not simulated in the model, therefore, the calculation result could have appreciable uncertainty over a short length, especially for high subcooling.

For low subcooling and saturated condition, this model gives satisfactory calculations for the experimental data of $\mathrm{p}=0.1-6 \mathrm{MPa}$, and $\mathrm{G}=90-1462 \mathrm{~kg} / \mathrm{m}^{2} \mathrm{~s}$, as exemplified in Fig.6(f).

\subsection{DFFB model}

The following two-fluid mechanistic model is based on the motion and energy equations, involving various equations for the wall-vapor-droplet heat transfer (Chen \& Chen, 1994b). The heat from the wall, $\mathrm{q}_{\mathrm{w}}$, is transferred to the vapor by convection, $\mathrm{q}_{\mathrm{c}}$, and radiation, $\mathrm{q}_{\mathrm{r}}$, as

with

$$
q_{w}=q_{c}+q_{r}
$$

and

$$
q_{c}=h_{c}\left(T_{w}-T_{v}\right)
$$

$$
q_{r}=\varepsilon \sigma_{S B}\left(T_{w}^{4}-T_{v}^{4}\right)
$$

where $h_{c}$ is the convective heat transfer coefficient, $\sigma_{S B}$ is the Boltzman's constant, and $\varepsilon$ the emissivity.

The vapor temperature is evaluated by

$$
T_{v}=T_{s}+\left(\frac{x_{e}}{x}-1\right) \frac{h_{f g}}{C_{p v}}
$$

where $x$ and $x_{e}$ are the actual quality and equilibrium quality, respectively.

From the heat balance equation, we have

$$
\frac{d x}{d z}=\frac{6(1-x) q_{d}^{\prime \prime}}{u_{l} h_{f g} \rho_{l} \delta}
$$

where $u_{l}$ and $\delta$ are the droplet velocity and diameter, respectively. The heat flux to the droplet, $q_{d}^{\prime \prime}$, includes the convective and radiative components, i.e.,

with

$$
q_{d}^{\prime \prime}=q_{d, c}+q_{d, r}
$$

$$
q_{d, r}=E \sigma_{S B}\left(T_{w}^{4}-T_{s}^{4}\right)
$$

and

$$
E=\frac{2}{3} \varepsilon \frac{\delta}{(1-\alpha) D}
$$


The vapor to droplet convective heat transfer is evaluated by Frossling correlation, as

$$
q_{d, c}^{\prime \prime}=\frac{k_{v}}{\delta}\left(2+0.552\left(\frac{\rho_{v}\left(u_{v}-u_{l}\right) \delta}{\mu_{v}}\right)^{0.5} \operatorname{Pr}_{v}^{0.33}\right)\left(T_{v}-T_{s}\right)
$$

The motion equation for the droplet gives

$$
\rho_{l} u_{l} \frac{d u_{l}}{d z}=\frac{3}{2} \frac{C_{d}}{\delta} \frac{\rho_{v}\left(u_{v}-u_{l}\right)^{2}}{2}-\left(\rho_{l}-\rho_{v}\right) g
$$

where the drag coefficient, $C_{d}$, is evaluated by Ingebo's correlation, as

$$
C_{d}=\frac{24\left(1+0.1 \operatorname{Re}_{d}^{0.75}\right)}{\operatorname{Re}_{d}} \text { for } \operatorname{Re}_{d}<1000
$$

with

$$
\operatorname{Re}_{d}=\frac{\rho_{v}\left(u_{v}-u_{l}\right) \delta}{\mu_{v}}
$$

and

$$
C_{d}=0.45 \text { for } \operatorname{Re}_{d} \geq 1000
$$

The wall to vapor convective heat transfer is predicted by the correlation derived from an author's convection heat transfer experiment in pure steam, multiplying an enhancement factor due to the disturbance induced by the droplets, as

$$
h_{c}=h_{0} F
$$

with

$$
h_{0}=0.0175 \frac{k_{v, f}}{D}\left(\frac{\rho_{v, f} u_{v} D}{\mu_{v, f}}\right)^{0.812} \operatorname{Pr}_{v, f}^{0.33}
$$

The factor $F$ would be related with pressure and quality. To fit the calculations with the experimental results, the following expression for $F$ is proposed with $\mathrm{p}$ in $\mathrm{MPa}$, as

$$
F=2.32(1+0.1 p) e^{-12 x}+1
$$

For the DFFB occurring from the dryout of liquid film of annular flow, the initial droplet diameter, $\delta_{0}$, is evaluated by a modification of Nujiyama-Tanazawa equation, as

$$
\delta_{0}=798 \frac{\rho_{v}}{G x_{0}}\left(\frac{\sigma}{\rho_{l}}\right)^{0.5}\left(\frac{\mu_{v}}{G x_{0} D}\right)^{a}
$$

where

$$
a=0.63-0.1 p \text { for } p<1.3 M P a
$$


and

$$
a=0.5 \text { for } p \geq 1.3 M P a
$$

in which $\mathrm{p}$ is in MPa, $\delta$ and $D$ in $\mathrm{m}, G$ in $\mathrm{kg} / \mathrm{m}^{2} \mathrm{~s}, \mu$ in $\mathrm{kg} / \mathrm{ms}, \sigma$ in $\mathrm{kg} / \mathrm{m}, \rho_{l}$ and $\rho_{v}$ in $\mathrm{kg} / \mathrm{m}^{3}$.

The droplet has a maximum diameter, determined by the critical Weber number, $W e_{c}$, as

$$
\delta_{m}=\frac{W e_{c} \sigma}{\rho_{v}\left(u_{v}-u_{l}\right)^{2}}
$$

with $W e_{c}=5.0$.

For the DFFB occurring from the break-up of the IAFB, the initial diameter $\delta_{0}$ is taken as $\delta_{m}$. The onset of DFFB is defined by the criterion of droplet carryover (Yanomoto et al., 1987), as

$$
J_{g c}=\frac{3.57}{\sqrt{\rho_{g} C_{d}}}\left(\sigma g\left(\rho_{l}-\rho_{g}\right)\right)^{1 / 4} N_{\mu g}^{1 / 6}
$$

with

$$
N_{\mu g}=\frac{\mu_{g}}{\left[\rho_{g} \sigma \sqrt{\frac{\sigma}{g\left(\rho_{l}-\rho_{g}\right)}}\right]^{1 / 2}}
$$

where $J_{g c}$ is critical volumetric flux and $N_{\mu g}$ is viscosity number.

Assuming that the droplet break-up does not occur, so it varies with the actual quality, as

$$
\delta=\delta_{0}\left(\frac{1-x}{1-x_{0}}\right)^{1 / 3}
$$

The present model gives satisfactory predictions for the DFFB data over the range of pressure of $0.1-6 \mathrm{MPa}$, mass flux of $23-1020 \mathrm{~kg} / \mathrm{m}^{2} \mathrm{~s}$, as exemplified in Fig.8.

\subsection{Tabular method}

The film boiling models and phenomenological equations are time consuming, because they involve a large number of constitutive equations on the heat and momentum exchanges between phases and the evaluations of many properties. Furthermore, they are only applicable for the specific test condition of individual investigator. In recent years, the tabular method has been widely accepted due to its advantages of high accuracy, wide applicable range and convenience for application and updating.

\subsection{1 fully-developed film boiling heat transfer coefficients}

Based on over 15000 film boiling data points, Leung et al. (1997) have developed a look-up table for the fully-developed film boiling heat transfer coefficients in tubes with vertical upward flow. It contains a tabulation of normalized heat transfer coefficients at discrete local parameters of pressure $(0.1-20 \mathrm{MPa}$ in 14 steps $)$, mass flux $\left(0-7000 \mathrm{~kg} / \mathrm{m}^{2} \mathrm{~s}\right.$ in 12 
steps), quality (-0.2 - 1.2 in 11 steps) and heat flux $\left(0.05-3 \mathrm{MW} / \mathrm{m}^{2}\right.$ in 9 steps). The agreements of the calculations of this table for surface temperatures with the data are $6.7 \%$ in r.m.s.

The range of flow conditions of the data base is presented in Fig.16. It shows significant gaps in the range of low flows and medium pressures, where the thermal non-equilibrium could be significant, and the heat transfer could be strongly history-dependent.

\subsubsection{Thermal non-equilibrium parameter}

For estimation of the heat transfer coefficient in the region of lower flow, a table for thermal non-equilibrium parameter has been proposed (Chen \& Chen 1998). It formulates the nonequilibrium parameter, $K_{0}$, for tube of $\mathrm{D}=8 \mathrm{~mm}$ at concrete values of the pressure $\mathrm{p}$, mass flux $\mathrm{G}$ and quality at the dryout point $\mathrm{x}_{0}$ (Tab.1). The values of $K_{0}$ were produced from the calculations of DFFB model, which was validated by the data of vapor temperature measured at the steady-state film boiling experiments.

The $K$ is assumed to be related with the diameter, local quality and heat flux, as expressed by

$$
K=K_{0} F_{d} F_{x} F_{q}
$$

where, $F_{d}, F_{x}$ and $F_{q}$ are the correction factors for the effects of diameter, local quality and heat flux, respectively.

For the present experimental results, the $F_{d}$ is evaluated by

$$
F_{d}=\left(\frac{D}{0.008}\right)^{0.26}
$$

The calculation indicates that from the dryout point the $K$ increases rapidly, while after a short distance it does not vary appreciably. So it is simply accounted by a proper $K_{0}$ with $F_{x}=1$. At present the expression for the $F_{q}$ is not available and is also set to be 1.0.

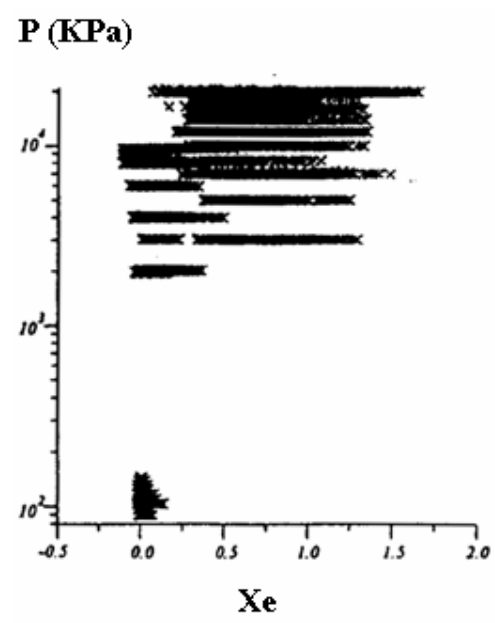

(a)

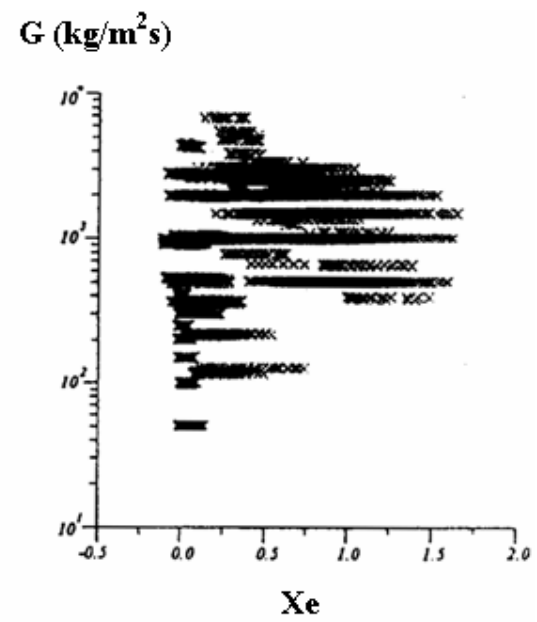

(b)

Fig. 16. Ranges of conditions of the data base for Leung's Look-up table (Leung, et al., 1997) 
Having the value of $K$, the actual quality and the vapor temperature are evaluated by

$$
K=\frac{x-x_{0}}{x_{e}-x_{0}}
$$

and

$$
T_{v}=T_{s}+\left(\frac{x_{e}}{x}-1\right) \frac{h_{f g}}{C_{p g}}
$$

Then, the wall temperature is calculated by

$$
T_{w}=T_{v}+\left(q_{w}-q_{r}\right) / h_{c}
$$

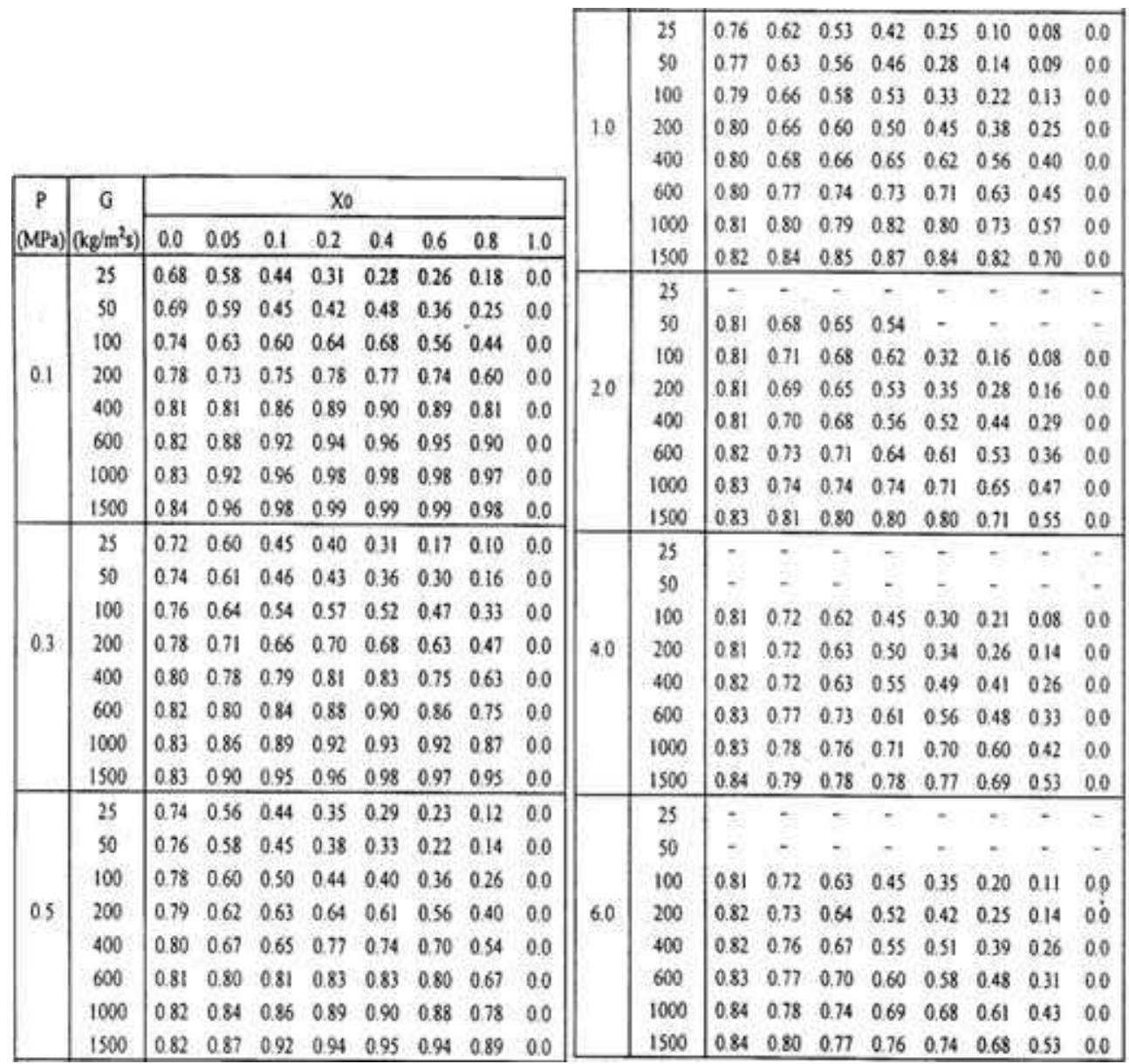

Table 1. Table of $K_{0}$ with parameters p, G and $x_{0}$ 
where $h_{c}$ is the convective heat transfer coefficient, and $q_{r}$ is the radiative heat flux. They are evaluated by Eq.(25) and (18), respectively.

The present tabular method was based on 2192 experimental data in tubes of $\mathrm{D}=6.7$ and 12 $\mathrm{mm}$ for pressure of $0.1-5.8 \mathrm{MPa}$, mass flux of $23-1462 \mathrm{~kg} / \mathrm{m}^{2} \mathrm{~s}$ and local equilibrium quality of $0-1.36$. The conditions of the data base are shown in Fig. 17. The agreements of the calculations of wall temperatures with the data are $7.2 \%$ in r.m.s., as exemplified in Fig 18.

\section{Conclusions}

Using the directly heated hot patch technique the film boiling experiments have been performed at stead-state in tubes of $6.7-20 \mathrm{~mm}$ with water flowing upward, covering the ranges of pressure of $0.1-6 \mathrm{MPa}$, mass flux of $23-1462 \mathrm{~kg} / \mathrm{m}^{2} \mathrm{~s}$ and inlet quality of $-0.15-$ 1.0. The characteristics of film boiling have been investigated systematically, including the inverted annular film boiling, the dispersed flow film boiling and the minimum film boiling temperature. A great number of data of heat transfer coefficients, the minimum film boiling temperatures and the vapor superheats have been obtained. They fill the gaps of the data base and understanding in the regions of lower flow and medium pressure.

The film boiling is characterized by non-equilibrium between phases in both the velocity and temperature, associated with extremely complicated parametric trends and strongly history-dependent feature of the heat transfer coefficients. Two-fluid mechanistic models and tabular method have been proposed to predict the heat transfer coefficients satisfactorily for the inverted annular film boiling with saturated or low subcooling conditions and the dispersed flow film boiling.

The results show that the heat transfer coefficient near the dryout point is closely relative to the preceding heating. Therefore the IAFB model without encountering for this effect could have appreciable uncertainties over a short length for higher subcooling condition.

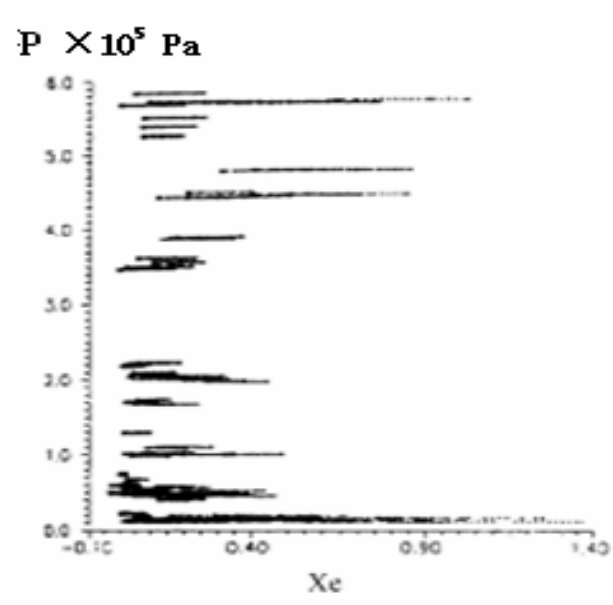

(a)

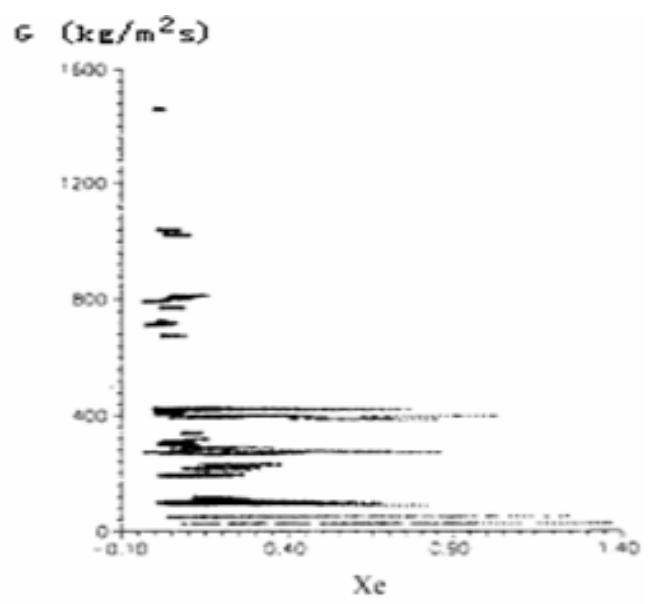

(b)

Fig. 17. Ranges of conditions of the present film boiling data for $x_{e}>0$ (Chen \& Chen 1998) 


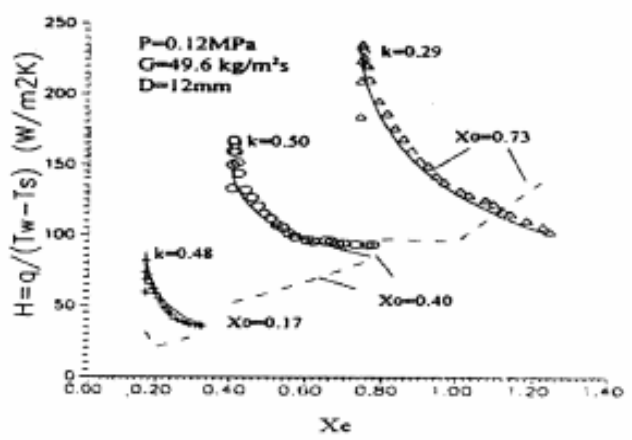

(a)

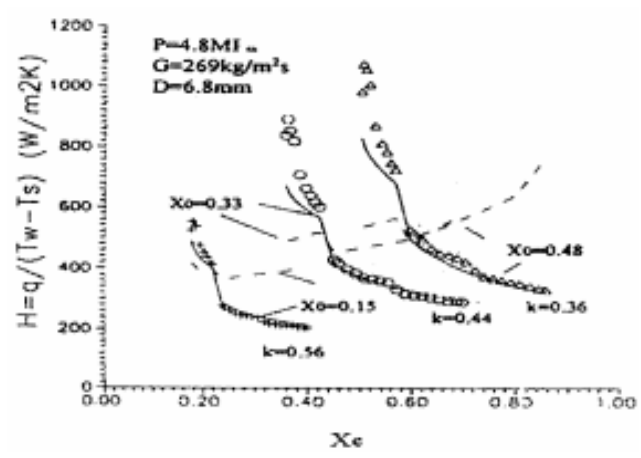

(c)

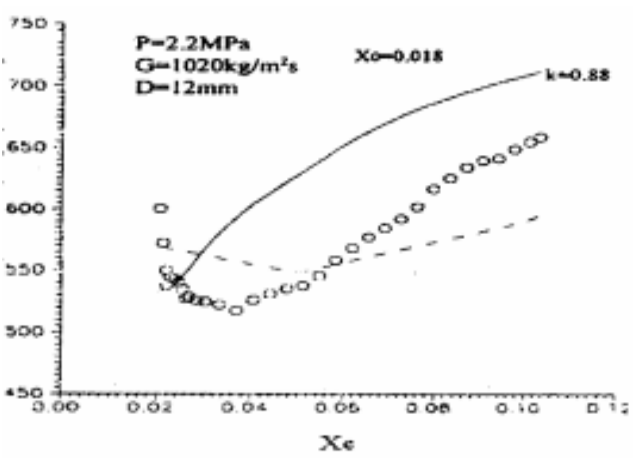

(b)

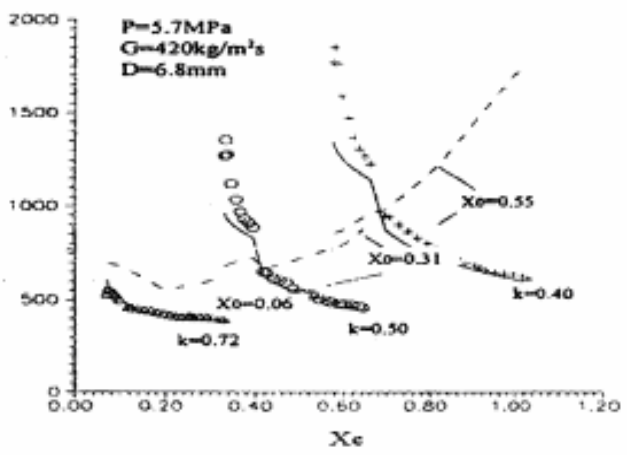

(d)

Fig. 18. Comparison of the calculation by tabular methods with experimental data (Chen \& Chen, 1998) - Table of Non-equilibrium parameter, --- Leung's Table ...

Note: in $(\mathrm{c}, \mathrm{d})$ two portions of boiling length were heated at different heat fluxes

\section{Nomenclature}

$\begin{array}{ll}C_{d} & \text { drag coefficient } \\ C_{p} & \text { specific heat } \\ \mathrm{D} & \text { diameter } \\ F & \text { enhancement or correction factor } \\ \mathrm{G} & \text { mass flux } \\ \mathrm{h} & \text { heat transfer coefficient } \\ \mathrm{h}_{\mathrm{fg}} & \text { latent heat } \\ \mathrm{K} & \text { heat conductivity } \\ \mathrm{L} & \text { distance from the dryout point } \\ \mathrm{p} & \text { pressure } \\ \mathrm{q} & \text { heat flux } \\ r & \text { radius } \\ \mathrm{T} & \text { temperature } \\ u & \text { velocity }\end{array}$




$\begin{array}{ll}x & \text { quality } \\ J_{g c} & \text { critical volumetric flux } \\ N_{\mu g} & \text { viscosity number } \\ N u & \text { Nusselt number } \\ \mathrm{Pr} & \text { Prandtl number } \\ \mathrm{Pr}_{\mathrm{t}} & \text { turbulent Prandtl numbe } \\ \operatorname{Re} & \text { Reynolds number } \\ \mathrm{We} & \text { Weber number; } \\ \alpha & \text { void fraction } \\ \delta & \text { droplet diameter, thickness of film } \\ \mu & \text { kinetic viscosity } \\ v & \text { dynamic viscosity } \\ \rho & \text { density } \\ \varepsilon & \text { eddy diffusivity, emissivity } \\ \sigma & \text { surface tension } \\ \sigma_{S B} & \text { Stefan-Boltzman constant } \\ \text { Subscript } \\ c & \text { critical, convective, core } \\ d & \text { droplet } \\ e & \text { equilibrium } \\ m & \text { maximum } \\ \text { min } & \text { minimum } \\ r & \text { radiation } \\ i & \text { interface } \\ l & \text { liquid } \\ s & \text { saturation } \\ v, \mathrm{~g} & \text { vapor } \\ w & \text { wall } \\ 0, \mathrm{DO} & \text { inlet (at dryout point) } \\ & \end{array}$

\section{References}

Analytis, G. Th. \& Yadigaroglu, G. (1987), Analytical Modelling of Inverted Annular Film Boiling, Nuclear Engineering and Design, Vol. 99, PP 201 - 212

Arrieta, L. \& Yadigaroglu, G. (1978), Analytical Model for Bottom Reflooding Heat Transfer in Light Water Reactor, EPPI-NP 756

Chen Y. \& Li, J. (1984), Subcooled Flow Film Boiling of Water at Atmospheric Pressure, in Two-phase Flow and Heat Transfer, X. J. Chen and T. N. Veziroglu, PP 141 - 150, Hemisphere Pub. Co., ISBN 0-89116-432-4

Chen,Y. (1987), Experimental Study of Inverted Annular Flow Film Boiling Heat Transfer of Water, in Heat Transfer Science and Technology, Bu-Xuan Wang, PP 627 - 634, Hemisphere Pub. Co., ISBN 0-89116-571-1,

Chen, Y.; Wang, J.; Yang, M. \& Fu, X. (1989a), Experimental Measurement of the Minimum Film Boiling Temperature for Flowing Water, in Multiphase Flow and Heat Transfer, Xue-Jun Chen, T. N. Veziroglu and C. L. Tien, Vol. 1, PP 393 - 400 17. Hemisphere Pub. Co., ISBN 1-56032-050-8 
Chen, Y.; Cheng, P.; Wang, J. \& Yang, M. (1989b), Experimental Studies of Subcooled and Low Quality of Film Boiling Heat Transfer of Water in Vertical Tubes at Moderate Pressure, Proc. $4^{\text {th }}$ Int. Topical Meeting on Nuclear Reactor Thermal-Hydraulics, Vol. 2, PP $1106-1110$

Chen Y., (1991), An Investigation of Dispersed Flow Film Boiling Heat Transfer of Water Experiment and numerical analysis, $2 d$ World Conf. on experimental fluid, heat transfer and thermodynamics, Yugoslawia

Chen, Y.; Chen, H.\& Zhu, Z. (1992), Post-Dryout Droplet Flow Heat TransferMeasurements of both wall and vapor superheat at stable condition, in Transport Phenomena Science and Technology, Wang B. X. PP 319 - 324, Higher Education Press, ISBN 7-04-004122-7/TH324

Chen, Y \& Chen, H. (1994a), An Experimental Investigation of Thermal Non-equilibrium in Dispersed Flow Film Boiling of Water, Proc. Int. Conf. on New Trends in Nuclear System Thermal-Hydraulics, Pisa Italy Vol.1 PP 31 - 37

Chen, Y. \& Chen, H. (1994b), A Model of Dispersed Flow Film Boiling Heat Transfer of Water, Proc. 10th Int. Heat Transfer Conf. Brighton UK, Vol. 7, PP 419 - 424

Chen, Y \& Chen, H. (1998), A Tabular Method for Prediction of the Heat Transfer during Saturated Film Boiling of Water in a Vertical Tube, , Proc. 11 ${ }^{\text {th }}$ Int. Heat Transfer Conf., Kyongju, Korea, Vol. 2, PP 163 - 168

Groeneveld, D. C. (1974), Effect of a Heat Flux Spike on the Downstream Dryout Behavior, $\mathrm{d}$ of Heat Transfer PP $121-125$

Groeneveld, D. C. and Gardiner, R. M. (1978), A Method of Obtaining Flow Film Boiling Data for Subcooled Water, Int. eI Heat Mass Transfer, Vol. 21 PP $664-665$

Groeneveld, D.C. \& Steward, J. C. (1982), The Minimum Film Boiling Temperature for Water during Film Boiling Collapse, Proc. $6^{\text {th }}$ Int. Heat Transfer conf. PP 393 - 398

Groeneveld, D.C. \& Snoek, C. W. (1984), A Comprehansive Examination of Heat Transfer Correlations Suitable for Reactor Safety Analysis, Multiphase Science and Technology, Vol.2

Groeneveld, D.C. (1988), Recent Developments in Thermalhydraulic Prediction Methods, Proc. Int. Topical Meeting on Thermalhydraulics of Nuclear Reactors, Seoul

Groeneveld, D. C. (1992), A Review of Inverted Annular and Low Quality Film Boiling, in Post-dryout Heat Transfer, Hewitt, Delhaye, Zuber, CRC Press, PP 327 - 366

Kirillov, P. L., et al. (1996), The Look-up Table for Heat Transfer Coefficient in Post-Dryout Region for Water Flowing in Tubes, FEI-2525

Leung, L. K. H.; Hammouda, N. \& Groeneveld, D. C. (1997), A look-up Table for Film Boiling Heat Transfer Coefficients in Tubes with Vertical Upward Flow, Proc. $8^{\text {th }}$ Int. Topical Meeting on Nuclear Reactor Thermal-Hydraulics, Kyoto, Japan, Vol. 2, pp $671-678$

Mossad, M. (1988), Sobcooled Film Boiling Heat Transfer to Flowing Water in Vertical Tube, Dr。-Ing. Thesis, Techn. Univ. Berlin, Berlin,

Mossad, M. \& Johannsen, K. (1989), A new Correlation for Subcooled and Low Quality Film Boiling Heat Transfer of Water at Pressures from 0.1 to $8 \mathrm{MPa}$, Proc. $4^{\text {th }}$ Int. Topical Meeting on Nuclear Reactor Thermal-Hydraulics, Vol. 2, PP 1111 - 1117

Plummer, D, N.; Iloeje, O. C.; Rohsenow, W. M.; Griffith, P. \& Ganic, E. (1974), Post Critical Heat Transfer to Flowing Liquid in a Vertical Tube, MIT Dpt. Of Mech. Eng. Report 72718-91 
Plummer, D. N.; Griffith, P. \& Rohsenow, W. M. (1977), Post-Critical Heat Transfer to Flowing Liquid in a Vertical Tube, Trans. ASME, Vol. 4, N.3, PP 151 - 158

Stewart, J. C. \& Groeneveld, D. C. (1982), Low Quality and Subcooled Film Boiling at Elevated Pressures, Nucl. Eng. Design. Vol. 67, PP 259 - 272

Swinnerton, D.; Hood, M. L. \& Pearson, K.G. (1988), Steady State Post-Dryout at Low Quality and Medium Pressure -Data Report, UKAEA AEEW-R 2267

Thermohudraulic relationships for advanced water cooled reactors, (2001), IAEA-TECDOC1203

Yonomoto, T.; Koizumi, Y. \& Tasaka, K, (1987) Onset Criterion for Liquid Entrainment in Reflooding Phase of LOCA, Nucl. Science and Technology, Vol. 24, No. 10, pp 798-810 


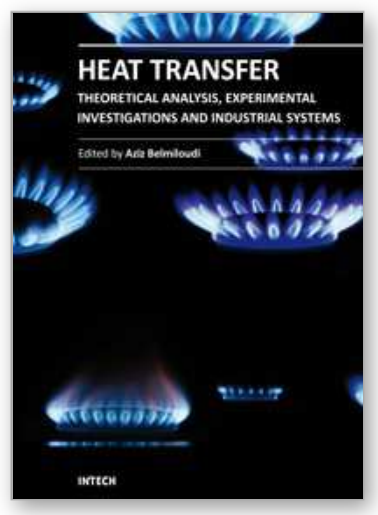

\author{
Heat Transfer - Theoretical Analysis, Experimental Investigations \\ and Industrial Systems \\ Edited by Prof. Aziz Belmiloudi
}

ISBN 978-953-307-226-5

Hard cover, 654 pages

Publisher InTech

Published online 28, January, 2011

Published in print edition January, 2011

Over the past few decades there has been a prolific increase in research and development in area of heat transfer, heat exchangers and their associated technologies. This book is a collection of current research in the above mentioned areas and discusses experimental, theoretical and calculation approaches and industrial utilizations with modern ideas and methods to study heat transfer for single and multiphase systems. The topics considered include various basic concepts of heat transfer, the fundamental modes of heat transfer (namely conduction, convection and radiation), thermophysical properties, condensation, boiling, freezing, innovative experiments, measurement analysis, theoretical models and simulations, with many real-world problems and important modern applications. The book is divided in four sections : "Heat Transfer in Micro Systems", "Boiling, Freezing and Condensation Heat Transfer", "Heat Transfer and its Assessment", "Heat Transfer Calculations", and each section discusses a wide variety of techniques, methods and applications in accordance with the subjects. The combination of theoretical and experimental investigations with many important practical applications of current interest will make this book of interest to researchers, scientists, engineers and graduate students, who make use of experimental and theoretical investigations, assessment and enhancement techniques in this multidisciplinary field as well as to researchers in mathematical modelling, computer simulations and information sciences, who make use of experimental and theoretical investigations as a means of critical assessment of models and results derived from advanced numerical simulations and improvement of the developed models and numerical methods.

\title{
How to reference
}

In order to correctly reference this scholarly work, feel free to copy and paste the following:

Yuzhou Chen (2011). Heat Transfer in Film Boiling of Flowing Water, Heat Transfer - Theoretical Analysis, Experimental Investigations and Industrial Systems, Prof. Aziz Belmiloudi (Ed.), ISBN: 978-953-307-226-5, InTech, Available from: http://www.intechopen.com/books/heat-transfer-theoretical-analysis-experimentalinvestigations-and-industrial-systems/heat-transfer-in-film-boiling-of-flowing-water

\section{INTECH}

open science | open minds

\author{
InTech Europe \\ University Campus STeP Ri \\ Slavka Krautzeka 83/A \\ 51000 Rijeka, Croatia
}

\author{
InTech China \\ Unit 405, Office Block, Hotel Equatorial Shanghai \\ No.65, Yan An Road (West), Shanghai, 200040, China \\ 中国上海市延安西路65号上海国际贵都大饭店办公楼405单元
}


Phone: +385 (51) 770447

Fax: +385 (51) 686166

www.intechopen.com
Phone: +86-21-62489820

Fax: +86-21-62489821 
(C) 2011 The Author(s). Licensee IntechOpen. This chapter is distributed under the terms of the Creative Commons Attribution-NonCommercialShareAlike-3.0 License, which permits use, distribution and reproduction for non-commercial purposes, provided the original is properly cited and derivative works building on this content are distributed under the same license. 